\title{
Triagem como Prática Humanizada em Saúde
}

\author{
Correia, Viviane Duarte; Siman, Maria da Conceição; Lemos, Maria da Penha \\ Instituto de Medicina Física e Reabilitação do Hospital das Clínicas da Faculdade de Medicina de \\ São Paulo — viviane.duarte@hc.fm.usp.br
}

INTRODUÇÃO: a triagem em serviços de reabilitação visa identificar a adequação do atendimento às condições e necessidades específicas do paciente, o que se aplica mediante critérios de elegibilidade. o processo requer abordagens capazes de superar o olhar puramente biomédico para as questões de saúde, na perspectiva do princípio de Integralidade e Igualdade do SUS, com foco na interdisciplinaridade. o processo é realizado por Médico, Assistente Social e Psicólogo, sendo o primeiro contato pessoal do candidato ao tratamento na Instituição. Traduz-se na interação entre profissional de saúde e usuário, criando uma rede comprometida com a defesa da vida e cidadania. Dentro da perspectiva da Política de Humanização do SUS, a integralidade é caracterizada pelo acolhimento, vínculo e cuidado nas práticas focadas na escuta das necessidades do paciente na sua totalidade, com articulação entre os saberes técnicos e a rede de serviços de saúde. a humanização do trabalho na saúde e reabilitação implica numa preocupação com condição de moradia, trabalho, educação, transporte, acesso a bens e serviços de saúde, de modo a garantir ao paciente condições de bem estar físico, mental e social, (art. 3 da Lei 8080/93SUS). OBJETIVOS: analisar a prática humanizada como processo de triagem; detectar as condições sócio demográficas do usuário que demanda à Instituição; identificar o perfil social dos pacientes em processo de triagem interdisciplinar. MÉTODO: a pesquisa é de natureza quantitativa, qualitativa e comparativa, constituída por dois grupos definidos, por meio dos protocolos de triagem do Serviço de Serviço Social, totalizando 403 pacientes no período de maio a setembro de 2011, e 436 no mesmo período de 2012. RESULTADOS: a maioria dos pacientes são pessoas do sexo feminino, com faixa etária de 51 a 60 anos, beneficiários do INSS, usuários do transporte público, compondo o grupo de "Pequenos Incapacitados", sem tratamento de reabilitação prévio, pertencentes à região Sul do município de São Paulo, sobretudo à de Campo Limpo. Observa-se fragilidade na rede de saúde, no que refere à articulação entre si e às demais políticas públicas, sobretudo à de transporte. Infere-se que o tratamento oferecido pela Instituição absorve a demanda com incapacidades físicas que não foi atendida pela rede básica e secundária de saúde. aos ineleitos, diante da necessidade de encaminhamento para atendimento na comunidade (contra-referência), observou-se a escassez e limitante nível de ofertas de serviços de reabilitação na rede SUS primária e secundária. CONCLUSÃO: Constata-se a necessidade de planejamento, intersetorialidade e integração da Rede SUS para a obtenção de ganhos na equidade, acessibilidade e qualidade no atendimento. a triagem interdisciplinar contribui para uma prática humanizada na saúde, com escuta técnica e acolhimento qualificados, de acordo com a Política de Humanização do SUS HumanizaSUS.

Correia, Viviane Duarte; Siman, Maria da Conceição; Lemos, Maria da Penha. Triagem como Prática Humanizada em Saúde. In: Anais do Congresso Internacional de Humanidades \& Humanização em Saúde [= Blucher Medical Proceedings, num.2, vol.1]. São Paulo: Editora Blucher, 2014. ISSN 2357-7282 DOI 10.5151/medpro-cihhs-10275 